\title{
Genome-wide association study of Mycobacterium avium subspecies Paratuberculosis infection in Chinese Holstein
}

Yahui Gao ${ }^{1}$, Jianping Jiang ${ }^{1}$, Shaohua Yang ${ }^{1}$, Jie Cao ${ }^{2}$, Bo Han ${ }^{1}$, Yachun Wang ${ }^{1}$, Yi Zhang ${ }^{1}$, Ying Yu', Shengli Zhang' ${ }^{1}$, Qin Zhang ${ }^{1}$, Lingzhao Fang ${ }^{3}$, Bonnie Cantrell ${ }^{4}$ and Dongxiao Sun ${ }^{{ }^{*}}$

\begin{abstract}
Background: Paratuberculosis is a contagious, chronic and enteric disease in ruminants, which is caused by Mycobacterium avium subspecies paratuberculosis (MAP) infection, resulting in enormous economic losses worldwide. There is currently no effective cure for MAP infection or a vaccine, it is thus important to explore the genetic variants that contribute to host susceptibility to infection by MAP, which may provide a better understanding of the mechanisms of paratuberculosis and benefit animal genetic improvement. Herein we performed a genome-wide association study (GWAS) to identify genomic regions and candidate genes associated with susceptibility to MAP infection in dairy cattle.

Results: Using Illumina Bovine 50 K (54,609 SNPs) and GeneSeek HD (138,893 SNPs) chips, two analytical approaches were performed, GRAMMAR-GC and ROADTRIPS in 937 Chinese Holstein cows, among which individuals genotyped by the $50 \mathrm{~K}$ chip were imputed to HD SNPs with Beagle software. Consequently, 15 and 11 significant SNPS $\left(P<5 \times 10^{-5}\right)$ were identified with GRAMMAR-GC and ROADTDRIPS, respectively. A total of 10 functional genes were in proximity to (i.e., within $1 \mathrm{Mb}$ ) these SNPS, including IL4, IL5, IL13, IRFI, MyD88, PACSINI, DEF6, TDP2, ZAP70 and CSF2. Functional enrichment analysis showed that these genes were involved in immune related pathways, such as interleukin, T cell receptor signaling pathways and inflammatory bowel disease (IBD), implying their potential associations with susceptibility to MAP infection. In addition, by examining the publicly available cattle QTLdb, a previous QTL for MAP was found to be overlapped with one of regions detected currently at 32.5 Mb on BTA23, where the TDP2 gene was anchored.
\end{abstract}

Conclusions: In conclusion, we identified 26 SNPs located on 15 chromosomes in the Chinese Holstein population using two GWAS strategies with high density SNPs. Integrated analysis of GWAS, biological functions and the reported QTL information helps to detect positional candidate genes and the identification of regions associated with susceptibility to MAP traits in dairy cattle.

Keywords: GWAS, Paratuberculosis, SNP, Chinese Holstein

\footnotetext{
* Correspondence: sundx@cau.edu.cn

${ }^{1}$ Key Laboratory of Animal Genetics and Breeding of Ministry of Agriculture,

National Engineering Laboratory of Animal Breeding, College of Animal

Science and Technology, China Agricultural University, Beijing 100193, China

Full list of author information is available at the end of the article
}

(c) The Author(s). 2018 Open Access This article is distributed under the terms of the Creative Commons Attribution 4.0 International License (http://creativecommons.org/licenses/by/4.0/), which permits unrestricted use, distribution, and reproduction in any medium, provided you give appropriate credit to the original author(s) and the source, provide a link to the Creative Commons license, and indicate if changes were made. The Creative Commons Public Domain Dedication waiver (http://creativecommons.org/publicdomain/zero/1.0/) applies to the data made available in this article, unless otherwise stated. 


\section{Background}

Paratuberculosis, also known as Johne's disease (JD), is a contagious, chronic and enteric disease in ruminants caused by Mycobacterium avium subspecies paratuberculosis $(M A P)$ [1]. Symptoms of the disease include diarrhea and weight loss that eventually leads to death. This disease has a long period of incubation [2]. In cattle, JD cannot be diagnosed until symptoms are observed because animals can have MAP in their systems, but not have JD. It is always difficult to determine if an animal is at risk of contracting JD by screening for MAP. Once a cow shows symptoms of JD, there is no treatment so the only effective means to get rid of the disease is to cull. There is also no vaccine, so farmers cannot increase resistance to JD within their herds, which causes huge economic losses. The disease can easily be spread through the farm from contact with MAP infected feces or milk from infected cows. Changes in herd management could help to reduce JD, but understanding resistance in cattle will allow for better management of the disease. Genomic selection for disease-resistant animals may be a promising way to increase the ability of animals to resist $M A P$ infection. Exploring the genetic variants that contribute to host susceptibility to infection by $M A P$ is important both for animal genetic improvement programs and for a better understanding of the underlying mechanisms of disease.

Heritability estimates in Holstein and Jersey cows for infection with MAP range from 0.031 to 0.283 [3-13]. By employing a case-control design, several functional genes have been reported to be associated with susceptibility to $M A P$ infection in cattle. This includes CLEC7A [14], IL10RA [15], IL12RB1, IL12RB2, IL23R, IFNGR2 [16], NOD2 [17-19], PGLYRP1 [20], SLC11A1 [21, 22], SP110 [23], TLR1 [24, 25], TLR2 [24-26] and TLR4 [24, 25]. Multiple QTLs are located on BTA7 [27] and BTA20 [28]. These studies indicated that genetic factors contribute to the susceptibility of MAP infection in cattle.

Nowadays, genome-wide association study (GWAS) is a popular strategy to identify candidate genes for specified traits. Earlier GWAS studies for MAP infection in Holstein cattle were based on serum ELISA, milk ELISA, fecal culture test or a comprehensive test for MAP infection [29-37]. Various SNPs associated with susceptibly to MAP infection are extensively distributed across all autosomes in different Holstein cattle populations. Several candidate genes for $M A P$ infection were subsequently identified, such as EDN2, PRDM1, LAMB4, DLD, LDLRAD3, CACNA1B, TIMD4, ITK, C, BTN1A1 and TDP2 [29-37]. Zare et al. reported 9 SNPs on BTA3, BTA6, BTA17 and BTA23 in the US Jersey cattle population and suggested SLC17A1, UBD, HIVEP1, CCDC17, ZNF684, UBE2L3, UBE2K, FAM109A and $F A M 5 C$ genes as candidates for susceptibly to MAP infection [35]. In the present study, the objectives were to identify genetic markers and genomic regions that are associated with susceptibility to MAP infection by performing a GWAS in Chinese Holsteins, and to provide further molecular information for the MAP resistance breeding program.

\section{Methods \\ Data description}

A total of 8214 Chinese Holstein cows from 7 dairy farms belonging to the Beijing Sanyuan Dairy Farm Center were fed under the same management throughout this study. We collected a $500 \mu \mathrm{L}$ blood sample from the caudal vein of each cow and performed a regular quarantine inspection of the farms during September 2014. Serum extracted from blood samples were stored at $4{ }^{\circ} \mathrm{C}$ until testing; within 5 days after collection. The commercially available, ELISA kit (IDEXX Laboratories, Inc., Westbrook, ME, USA) was used according to the manufacturer instructions to measure the antibody levels of each serum sample. The MAP status of an animal was expressed as a percentage of the sample to positive ratio $(\mathrm{S} / \mathrm{P})$ with the formula: $\mathrm{S} / \mathrm{P}$ ratio $=[($ optical density $(\mathrm{OD})$ of the sample - OD of the negative control) / (OD of positive sample - OD of the negative control)], where $\leq 0.45$ is negative; $0.45<\mathrm{S} / P<0.55$ is suspect; $\mathrm{S} / P \geq 0.55$ is positive. ELISA suspect results were excluded because of their uncertainty. Out of the 8214 detected cows, 185 positive individuals (case) and 760 negative individuals (control) from 6 herds were used for GWAS. ELISA results were employed as a binary trait $(0=$ negative, $1=$ positive).

\section{Genotyping}

The individuals in this study were divided into 2 sub-groups for genotyping. Five hundred and thirty three cows belonging to the first sub-group were genotyped with the Illumina Bovine SNP50 BeadChip (54,609 SNPs, Illumina, San Diego, CA, USA) after extracting DNA from whole blood using routine procedures. DNA was isolated from whole blood with a commercially available kit, the DP318 Blood DNA Kit (Tiangen Biotech Co., China). The DNA of the remaining 412 cows in the second sub-group were extracted from hair by GeneSeek with QIAamp DNA Mini Kit (QIAGEN Inc., Valencia, CA, USA) and then genotyped with the GeneSeek Genomic Profiler HD v2 (138,893 SNPs, GeneSeek, Lincoln, NE, USA). The genotype data were deposited in the Additional files (Additional files 1 and 2).

\section{Imputation and quality control}

To make full use of SNPs originating from the GeneSeek Genomic Profiler HD v2 (GeneSeek), individuals genotyped by the Illumina Bovine SNP50 BeadChip were 
imputed to GeneSeek Genomic Profiler HD v2. Imputation was performed using BEAGLE 3.3.2 [38] default options. Allelic $\mathrm{R}^{2}$ was estimated as an indicator of imputation accuracy based on the genotype probabilities.

To further evaluate imputation accuracy, we randomly selected 100 cows genotyped by the high-density chip, obtained the common SNPs between the two panels, and masked genotypes of SNPs left. We classified this small subset of cows as the study population, while the remaining cows genotyped by the high-density panel were classified as the reference population. After imputation, we compared the imputed and masked actual genotypes of the selected 100 cows to calculate the percentage of genotypes that are consistent between them.

Then we implemented PLINK [39] and removed SNPs with call rates $<95 \%$, minor allele frequencies $<0.01$, a deviation from Hardy-Weinburg equilibrium (HWE) $P$ values $<10^{-6}$ and $>5 \%$ missing genotypes. A dataset containing 109,607 SNPs and 937 animals (182 cases and 755 controls) was used for further analysis. All SNP positions were determined according to the Bos taurus UMD 3.1 assembly [40].

\section{Population stratification}

Differences in allele frequencies between subpopulations of admixed populations can lead to false association in a GWAS [41]. In order to determine whether stratification exists in our study population, a principle component analysis (PCA) was performed by GCTA 1.24 [42] and results were visualized by $\mathrm{R}$ 3.3.1 [43].

\section{GWAS}

\section{GRAMMAR-GC}

We performed a GWAS using the Genome-wide Rapid Association using Mixed Model and Regression-Genomic Control (GRAMMAR-GC) approach $[44,45]$, a single-marker method implemented within the GenABEL package [46] for $\mathrm{R}$ [43]. This approach can account for the potential population structure and infer relationships using SNP data without pedigree information. There have been multiple GWAS studies in cattle that utilized this approach [31, 34-37]. GRAMMAR-GC is comprised of three steps that use the regression of phenotypes on the genotypes of individuals for one SNP at a time. First, to account for familial dependence among individuals, phenotypes were corrected by conducting a polygenic analysis using a genomic kinship matrix based on the SNP genotypes. Residuals from the polygenic analysis were then used as dependent quantitative traits for association analysis of each SNP with a linear regression model. Finally, genomic control (GC) was applied to correct the test statistic using the genomic inflation factor $(\lambda)$, which is the regression coefficient of the observed statistic on the expected statistic. We performed an association test for each SNP based on the following linear mixed model:

$$
y=W \alpha+x \beta+u+\varepsilon,
$$

where $\mathbf{y}$ is the liability vector for case/control observations; $\mathbf{W}$ is a matrix of covariates (fixed effects that contain herd and parity); $\boldsymbol{\alpha}$ is a vector of the corresponding coefficients including the intercept; $\mathbf{x}$ is a vector of genotypes of a marker at the locus tested; $\boldsymbol{\beta}$ is the effect size of the marker; $\mathbf{u}$ is a vector of random polygenic effects with a covariance structure as $\boldsymbol{\beta} \sim \mathrm{N}\left(0, \mathrm{~V}_{\mathrm{g}}\right), \mathrm{V}_{\mathrm{g}}$ is the polygenic additive variance; $\boldsymbol{\varepsilon}$ is a vector of residual errors with $\boldsymbol{\varepsilon} \sim \mathrm{N}\left(0, \mathbf{I} V_{\mathrm{e}}\right)$, $\mathbf{I}$ is the identity matrix, and $V_{\mathrm{e}}$ is the residual variance component.

In general, for GRAMMAR-GC, the value $T^{2} / \hat{\zeta}$ of each SNP with one-degree freedom is compared with $X_{1}^{2}$ to determine whether the locus is significantly associated with the trait. Here $T_{k}^{2}=\hat{\beta}_{k}^{2} / \operatorname{var}\left(\widehat{\beta_{k}}\right)$, where $\widehat{\beta_{k}}$ is the effect of the $k^{\text {th }}$ SNP. The deflation factor $\zeta$ is estimated as $\zeta=$ median $\left(T_{1}^{2}, T_{2}^{2}, \ldots, T_{k}^{2}\right) / 0.456$.

\section{ROADTRIPS}

A second GWAS approach was implemented with ROADTRIPS 2.0 [47]. An important advantage of ROADTRIPS 2.0 is that it can analyze data with pedigree information and population admixture simultaneously. Based on the genome-wide SNP data, an empirical covariance matrix was constructed to adjust for potential population admixture and relatedness among individuals and maintain the advantage of utilizing known pedigree information when available. The ROADTRIPS 2.0 test statistic based on $\chi_{1}^{2}$ distribution for each SNP takes the form:

$$
\frac{\left(\mathbf{V}^{T} \mathbf{Y}\right)^{2}}{\hat{\sigma}^{2} \mathbf{V}^{T} \hat{\mathbf{Y}} \mathbf{V}} \sim X_{1}^{2}
$$

Here $\mathbf{Y}=\left(Y_{1}, Y_{2}, \ldots, Y_{\mathrm{n}}\right)^{T}$, is genotype vector at a test SNP for $\mathrm{n}$ individuals (coded using an allelic coding). $\mathrm{V}$ is a vector of length $\mathrm{n}$ coding for phenotype information (disease status) and known relationships. $\hat{\sigma}^{2} \hat{\boldsymbol{\Psi}}$ is an estimate of the null variance/covariance matrix of $\mathbf{Y} . \hat{\sigma}^{2}$ is an estimate of $\operatorname{Var}(\mathrm{Y})$ in an outbred population and $\hat{\Psi}$ is an estimated matrix used to simultaneously adjust for unknown relatedness/pedigree relationship errors and population stratification.

ROADTRIPS 2.0 provides three association tests named RM test, RX test and RW test. According to the authors' recommendation, the RM test is the most powerful among the three tests when pedigree information is available. Compared with the RX test and the RW test, the RM test can use the phenotypic information of 
individuals with missing genotypes provided that they have a genotyped relative at the tested marker. Considering the features of the RM test and the data structure of this study being based on a corrected pedigree, we adopted the RM test for association analysis. $P$ values of SNPs were derived from an asymptotic chi-square distribution with 1 degree of freedom. In addition, the fixed effects used here was the same as above.

Following the suggestion of the Welcome Trust Case Control Consortium [48], two $P$ value thresholds of $5 \times$ $10^{-7}$ and $5 \times 10^{-5}$ were considered as genome-wide "strong" and "moderate" association respectively.

\section{Gene contents and functional annotation}

Using BioMart in the Ensembl database (Ensembl Genes 92), genes within $1 \mathrm{Mb}$ of the significant SNPs were retrieved based on the UMD 3.1 assembly. To provide insight into the functional enrichment of genes identified, we carried out GO (Gene Ontology) and Pathway analysis using KOBAS 3.0 [49]. KOBAS annotates a set of genes with putative pathways and disease relationships by mapping to genes with a known annotation. In addition, we compared the regions within $1 \mathrm{Mb}$ of the significant SNPs with the reported cattle to QTLs for JD tolerance and MAP susceptibility in the Animal QTL database (http://www.animalgenome.org/cgi-bin/ QTLdb/index) [50].

\section{Results}

\section{Imputation accuracy}

After imputation, we discarded SNPs with allelic $R^{2}<$ 0.85 and found an average allelic $\mathrm{R}^{2}$ of $96.7 \%$ for imputed genotypes. Then we took a small subset including 100 cows genotyped by the high-density chip for calculating the imputation accuracy. Finally, the percentage of consistent genotypes was $97.03 \%$, which suggested a high accuracy of imputation.

\section{GWAS based on GRAMMAR-GC}

With GCTA 1.24, a slight population substructure was revealed (Additional file 3: Figure S1). The inflation factor $(\lambda)$, estimated to be $0.9399(\mathrm{SE}=0.0002)$, indicates population substructure was a minor issue and that our results can be accepted for further analysis. The GC-corrected $P$ values for the majority of SNPs corresponded well to the expected $P$ values under the null hypothesis of no association. However, a few departures which mean the $P$ values of these SNPs were higher than the expected $P$ values under the null hypothesis indicated associations with the trait being studied (Additional file 4: Figure S2). As shown in Tables 1, 2 SNPs passed the strong association threshold and 13 SNPs passed the moderate threshold (Fig. 1).
Table 1 Results of GRAMMAR-GC genome-wide association analysis for susceptibility to MAP infection $(\mathrm{df}=1)$

\begin{tabular}{llll}
\hline SNP & BTA & Position & $P$ value \\
\hline BovineHD2200003382 & 22 & $11,359,993$ & $1.13 \mathrm{E}-14$ \\
BovineHD0700017491 & 7 & $60,947,866$ & $2.76 \mathrm{E}-09$ \\
BovineHD0700007000 & 7 & $25,403,106$ & $2.54 \mathrm{E}-06$ \\
BovineHD2300007824 & 23 & $28,173,531$ & $6.90 \mathrm{E}-06$ \\
BTB-00030699 & 1 & $61,806,466$ & $8.85 \mathrm{E}-06$ \\
BovineHD0800002130 & 8 & $6,659,432$ & $1.18 \mathrm{E}-05$ \\
BovineHD0200036516 & 2 & $125,910,848$ & $1.49 \mathrm{E}-05$ \\
Hapmap44402-BTA-73818 & 13 & $27,398,154$ & $1.64 \mathrm{E}-05$ \\
BovineHD4100015938 & 23 & $8,975,441$ & $1.98 \mathrm{E}-05$ \\
ARS-BFGL-BAC-29490 & 23 & $20,166,517$ & $2.75 \mathrm{E}-05$ \\
BovineHD2300009447 & 23 & $32,516,000$ & $3.82 \mathrm{E}-05$ \\
ARS-BFGL-NGS-36626 & 18 & $54,052,117$ & $4.50 \mathrm{E}-05$ \\
BovineHD0700006647 & 7 & $24,259,310$ & $4.62 \mathrm{E}-05$ \\
BovineHD1800010086 & 18 & $33,293,455$ & $4.62 \mathrm{E}-05$ \\
BovineHD2700011748 & 27 & $40,498,309$ & $4.83 \mathrm{E}-05$ \\
\hline
\end{tabular}

\section{GWAS based on ROADTRIPS}

RM test was implemented for the association analysis. As shown in Additional file 5: Figure S3, the $P$ values for the majority of SNPs exhibited a good correspondence to the expected values with a limited number of SNPs indicating their associations with the studied trait. In total, 4 and 7 SNPs passed the threshold of strong and moderate association, respectively (Fig. 2, Table 2).

\section{Gene contents and functional annotation}

There were 15 significant SNPs detected by GRAMMAR-GC in total. Utilizing BioMart in the Ensembl database (Ensembl Genes 92), we obtained the 232 IDs for genes located within or overlapped with the regions nearby these SNPs $(<1 \mathrm{Mb})$ (Additional file 6:

Table 2 Results of ROADTRIPS genome-wide association analysis for susceptibility to MAP infection $(\mathrm{df}=1)$

\begin{tabular}{llll}
\hline SNP & BTA & Position & $P$ value \\
\hline BTB-01281916 & 3 & $71,760,025$ & $1.21 \mathrm{E}-08$ \\
Hapmap49590-BTA-38619 & 16 & $35,765,411$ & $4.37 \mathrm{E}-08$ \\
ARS-BFGL-NGS-25380 & 11 & $2,260,123$ & $1.98 \mathrm{E}-07$ \\
BTB-00452217 & 11 & $2,983,521$ & $2.81 \mathrm{E}-07$ \\
BTA-79476-no-rs & 7 & $60,933,059$ & $9.71 \mathrm{E}-07$ \\
BovineHD0700006447 & 7 & $23,495,415$ & $2.10 \mathrm{E}-06$ \\
BovineHD0200035709 & 2 & $123,174,023$ & $7.90 \mathrm{E}-06$ \\
ARS-USDA-AGIL-chr6-117,920,790-000733 & 6 & $117,920,790$ & $1.87 \mathrm{E}-05$ \\
BovineHD2400014963 & 24 & $52,857,741$ & $3.33 \mathrm{E}-05$ \\
Hapmap39753-BTA-50189 & 20 & $28,186,842$ & $4.80 \mathrm{E}-05$ \\
BovineHD1300015832 & 13 & $55,734,067$ & $4.92 \mathrm{E}-05$ \\
\hline
\end{tabular}




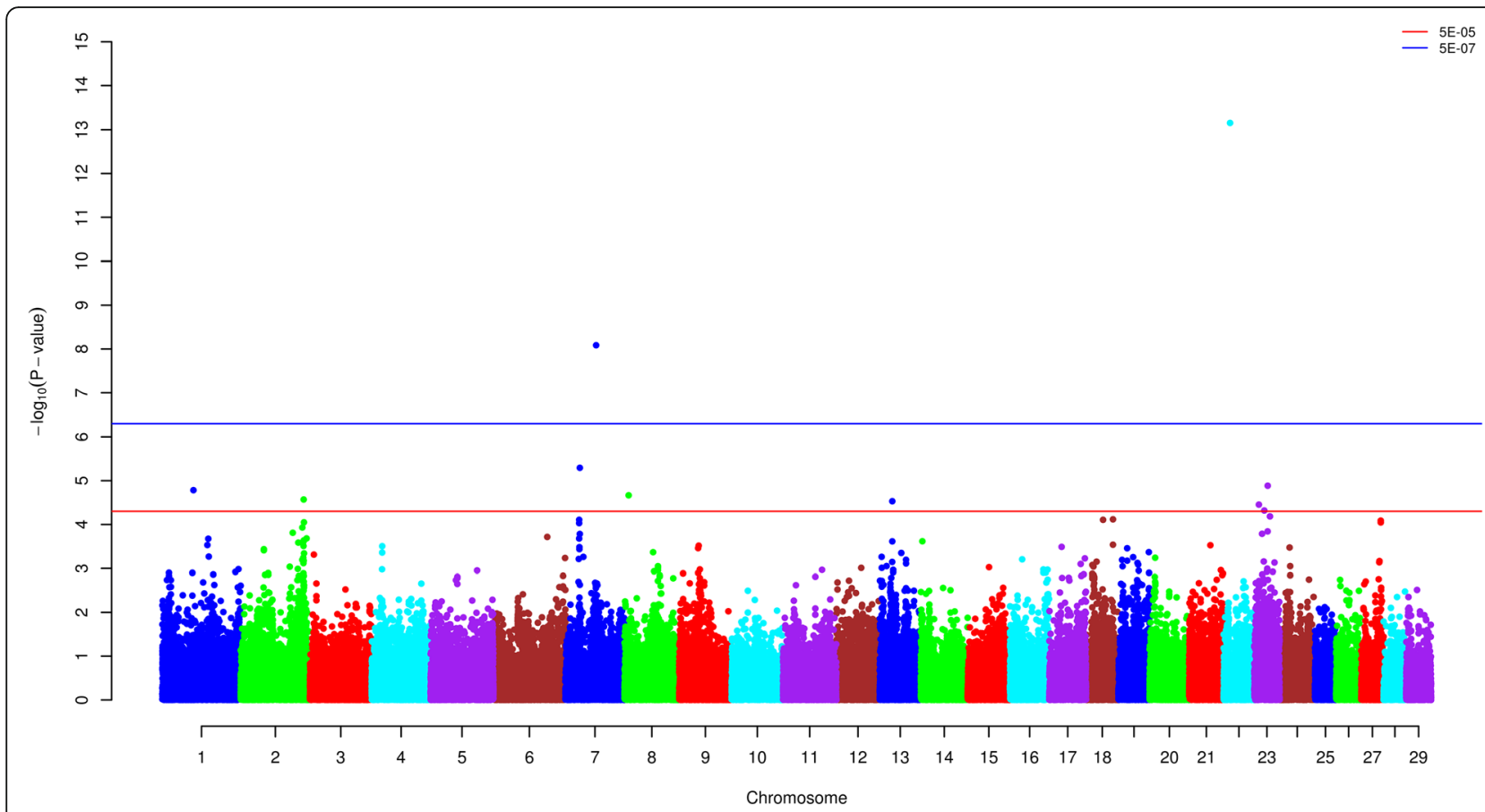

Fig. 1 Manhattan plot of genome-wide SNPs obtained using GRAMMAR-GC. Each dot represents the result from the test of association for a single SNP. Minus $\log 10$ of the $P$ value is indicated on the $y$-axis and map location of the SNP is indicated on the $x$-axis. Thresholds represent $P$ values of $5 \mathrm{E}-05$ and $5 \mathrm{E}-07$ for moderate and strong associations, respectively

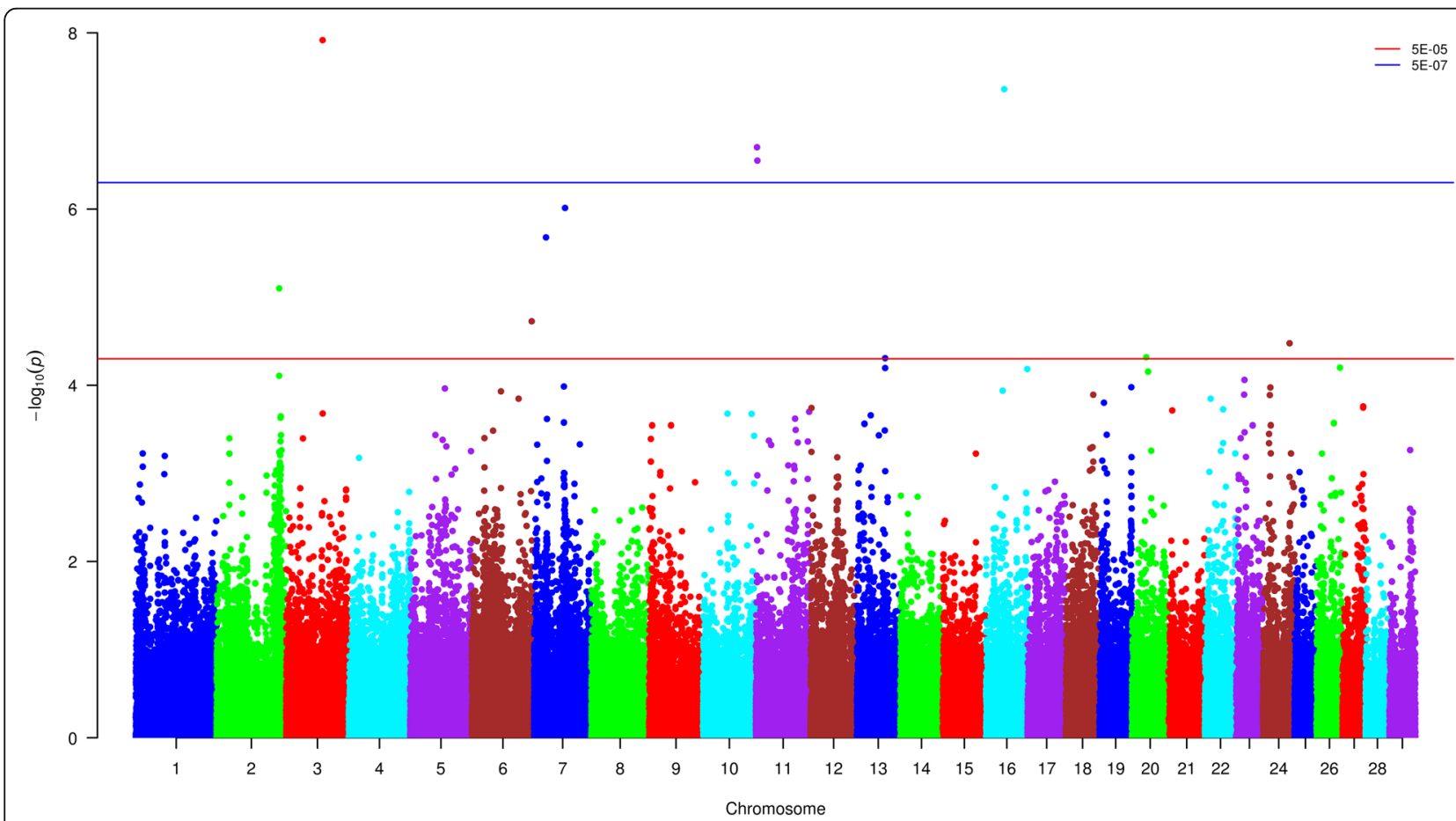

Fig. 2 Manhattan plot of genome-wide SNPs obtained using ROADTRIPS. Each dot represents the result from the test of association for a single SNP. Minus $\log 10$ of the $P$ value is indicated on the $y$-axis and map location of the SNP is indicated on the $x$-axis. Thresholds represent $P$ values of $5 \mathrm{E}-05$ and $5 \mathrm{E}-07$ for moderate and strong associations, respectively 
Table S1). Based on the 11 significant SNPs detected by ROADTRIPS, 123 functional gene IDs were identified (Additional file 7: Table S2). After the combination of results, a total of 343 genes were obtained, including 283 protein-coding genes, 21 miRNA genes, 6 pseudogenes, 12 snRNA, 15 snoRNA, 4 rRNA and 2 miscRNA (Additional file 8: Table S3).

GO and Pathway analysis were performed by KOBAS 3.0 to determine the biological functions of the 343 genes. Finally, 348 significant GO terms were detected, including those related to immune response $(P<0.05)$, such as immune response-regulating signaling pathway, regulation of leukocyte proliferation and immune response-activating signal transduction. Fifteen significant pathways were found, including those related to immune responses $(P<0.05)$ such as autoimmune thyroid disease and enrichment of the interleukin signaling pathway (Additional file 9: Table S4). In addition, $T$ cell receptor signaling pathway [51] and inflammatory bowel disease (IBD) were detected but not significant.

\section{Quantitative traits locus overlapped with SNPs}

Until now, 6 JD tolerance and 161 MAP susceptibility QTLs have been reported in the cattle QTL database (http://www.animalgenome.org/cgi-bin/QTLdb/BT/

index). After comparing these QTLs with the regions within $1 \mathrm{Mb}$ of the 26 significant SNPs, 2 QTLs identified before [30, 37] located in BTA23 $(\sim 32.5 \mathrm{Mb})$ for MAP susceptibility were found. This implies the functional genes, such as TDP2 (tyrosyl-DNA phosphodiesterase 2) around these SNPs are likely candidates for $M A P$ susceptibility traits.

\section{Discussion}

There have been multiple GWASs conducted in different cattle population [29-37], and some candidate loci and genes have been identified. Although these studies found evidence of genomic regions associated with MAP infection, the consistency was not high. The genomic regions and genes regarded as candidates for the target traits were variable among previous studies. The difference between genomic regions identified by different studies is because of different trait definitions except for statistical methodologies [52]. There were four main definitions for infection cases in previous studies: ELISA positive [27, 31, 33], fecal culture positive [29], tissue culture positive [29] and comprehensive testing. Comprehensive testing includes tissue culture positive and fecal culture positive [29], ELISA positive or fecal positive [30], and ELISA positive or tissue culture positive [34].

We found 15 SNPs passing the threshold $\left(5 \times 10^{-5}\right)$ using GRAMMAR-GC with BTA23 owning the most SNPs. The most significant SNP, BovineHD2200003382
$(P=1.13 E-14)$ was identified on BTA22 (Table 1$)$. Similarly, 11 SNPs passed the threshold $\left(5 \times 10^{-5}\right)$ using ROADTRIPS with the most significant SNP, BTB-01281916 $(P=1.21 \mathrm{E}-08)$ identified on BTA3 (Table 2 ). There was no common SNP sharing between these two methods because of some possible reasons. Firstly, different computational principles can cause different significant SNPs. It is common that the discrepancy caused by this reason, such as the report of Alpay et al. [36] and Sallam et al. [37]. Both ROADTRIPS and GRAMMAR-GC can correct sample structure. The ROADTRIPS program uses the quasi-likelihood methods (implemented in the MQLS and similar statistics), to obtain known kinship coefficients, which then together with the empirical covariance matrix estimated from genomic data to correct for known and unknown relatedness and population structure [47]. Instead of pedigree, GRAMMAR-GC program uses genomic kinship matrix estimated through genomic marker data to adjust for average allele sharing or relatedness among sample individuals and thus remove genetic stratification [44, 45].

Secondly, JD is affected by multiple genetic loci and SNPs identified using different methods were polygenic in present study. Those SNPs with large effect may be captured more easily by multiple GWAS methods. In addition, the size of study population may cause discrepancy. The more individuals, the higher the accuracy of GWAS result. So it seems normal that different methods identifying different SNPs in present study. Thus, it seems normal that different methods identify different SNPs.

While no SNPs were identified by two methods, but the SNPs between the two methods were located close to each other on the same chromosome. For example on BTA2 $\sim 2.74 \mathrm{Mb}$ was found between BovineHD0200036516 (GRAMMAR-GC) and BovineHD0200035709 (ROADTRIPS), on BTA7 14.81 Kb was found between BovineHD0700017491 (GRAMMAR-GC) and BTA-79476-no-rs (ROADTRIPS), on BTA7 $\sim 1.91 \mathrm{Mb}$ was found between BovineHD0700007000 (GRAMMAR-GC) and BovineHD0700006447 (ROADTRIPS) and $\sim 0.76 \mathrm{Mb}$ was found between BovineHD0700006647 (GRAMMAR-GC) and BovineHD0700006447 (ROADTRIPS). Combining the results of these two methods, 26 significant SNPs were obtained. The most SNPs were found on BTA7 followed by BTA23.

Among the 26 significant SNPs detected by two methods, BovineHD0700006447 (23.5 Mb) located on BTA7 in this study was close to SNPs detected by Pant et al. (20.6 Mb $\sim 22.3 \mathrm{Mb})$ [27]. Genes nearby this SNP within less than $1 \mathrm{Mb}$ were IL4, IL5, IL13 and IRF1. The genes, IL4 (interleukin 4), IL5 and IL13 are type 2 cytokines, that may be the predominant cytokines produced by $\mathrm{CD} 4+$ and other $\mathrm{T}$ cells in lymph nodes during the 
subclinical infection of MAP [53]. As previously reported [54-56], in the clinical infection, the bovine MAP infection disease was characterized by a gradual shift in the immune responses from cell-mediated immune response to antibody mediated immune response while IL4, IL5 and IL13 can promote the $\mathrm{T}_{\mathrm{h}} 2$ antibody-mediated immune response. Therefore, these three genes might play important roles in the pathogenesis of the disease [27]. IRF1, interferon regulatory factor 1 , plays an important role in many immune responses including the Type $1\left(T_{h} 1\right)$ cell-mediated immune response. Cell mediated immunity is an important host defense mechanism against intracellular pathogens including MAP [57]. In addition, it can regulate the expression of many immune genes such as IL6, IL12B, and inducible nitric oxide synthase (NOS2) that function in the pathogenesis of human IBD [58-60].

The most significant SNP, BovineHD2200003382 detected by GRAMMAR-GC was located at $11.3 \mathrm{Mb}$ on BTA22. Genes within $1 \mathrm{Mb}$ of this location includes MyD88 (myeloid differentiation primary response gene 88) which encodes a cytosolic adapter protein that plays a central role in the innate and adaptive immune response. MyD88 functions as an essential signal transducer in the interleukin-1 and Toll-like receptor signaling pathways [61].

SNP BovineHD4100015938 on BTA23 $(8.98 \mathrm{Mb})$ was close to ARS-BFGL-NGS-109956 (7.84 Mb) and ARS-BFGL-NGS-115177 (7.87 Mb) reported by Zare et al. [35]. The genes near to these two SNPs included PACSIN1 and DEF6 that are related to immune response. PACSIN1 (protein kinase $\mathrm{C}$ and casein kinase substrate in neurons 1), belonging to a family of cytoplasmic phosphoproteins, participates in the regulation of endocytosis [62] and regulates the TLR7/9-mediated type I interferon response in plasmacytoid dendritic cells [63]. DEF6 (DEF6, guanine nucleotide exchange factor) is a guanine nucleotide exchange factor (GEF) for RAC (MIM 602048) and CDC42 (MIM 116952) that are highly expressed in $\mathrm{B}$ and $\mathrm{T}$ cells [64]. SNP BovineHD2300009447 (32.5 Mb) located on BTA23 was very close to ARS-BFGL-NGS-1938 (32.6 Mb) reported by Zare et al. in Jersey cattle [35], and close to ss 105264543 $(33.6 \mathrm{Mb})$ reported by Minozzi et al. in Holstein cattle [34]. Gene within $1 \mathrm{Mb}$ of this region was TDP2 (tyrosyl-DNA phosphodiesterase 2). This gene encodes a member of a superfamily of divalent cation-dependent phosphodiesterases. The encoded protein associates with CD40, tumor necrosis factor (TNF) receptor-75 and TNF receptor associated factors (TRAFs) that inhibits nuclear factor-kappa-B activation. In addition, TDP2 has sequence and structural similarities with APE1 endonuclease, which is involved in both DNA repair and the activation of transcription factors [65].
Interleukin, $\mathrm{T}$ cell receptor signaling pathway and inflammatory bowel disease (IBD) pathways are related to immune or inflammatory response. Two genes including ZAP70 and SRF, except for IL4, IL5, IL13 and MyD88 stated above, were involved in the immune biological processes. ZAP7O (zeta chain of T-cell receptor associated protein kinase 70) encodes an enzyme belonging to the protein tyrosine kinase family that plays a role in T-cell development and lymphocyte activation. This enzyme, phosphorylated on tyrosine residues upon $\mathrm{T}$-cell antigen receptor (TCR) stimulation, functions in the initial step of TCR-mediated signal transduction in combination with the Src family kinases, Lck and Fyn and plays an essential role in the process of thymocyte development [66]. In addition, mutations in this gene cause selective T-cell defect, a severe combined immunodeficiency disease characterized by a selective absence of CD8-positive T-cells [67]. Leite et al. investigated the expression of ZAP7O in cows naturally infected with $M A P$ and revealed that the surface expression of ZAP70 was decreased in CD4+ $\mathrm{T}$ cells of both subclinical and clinical animals indicating a change in $\mathrm{T}$ cell phenotype with disease state [68]. CSF2 (colony stimulating factor 2), also known as CSF and GMCSF, encodes a cytokine that controls the production, differentiation, and function of granulocytes and macrophages. This gene has been localized to a cluster of related genes at chromosome region $5 \mathrm{q} 31$ that are known to be associated with interstitial deletions in the 5q- syndrome and acute myelogenous leukemia. Other genes in the cluster include those encoding interleukins 4, 5, and 13 [69].

Furthermore, we found a region nearby the BovineHD2300009447 (BTA23, 32.5 Mb) overlapped with one QTL associated with MAP susceptibility. Combing this information with related genes found above, the $32 \sim 33 \mathrm{Mb}$ region of BTA23 may be a case of a genomic region associated with MAP infection, which corresponds to the report of Zare et al. [35].

The present study focused on the potential function of 10 candidate genes. Future analysis is necessary to investigate the biological processes and molecular mechanism of these genes to anchor immune alterations and possible triggers that result in clinical paratuberculosis.

\section{Conclusions}

We performed a case-control GWAS for MAP infection in Chinese Holstein cattle using two statistical approaches, GRAMMAR-GC and ROADTRIPS. Twenty-six significant SNPs located on 15 chromosomes were detected based on data after imputation. Ten genes within less than $1 \mathrm{Mb}$ of these SNPs were 
involved in immune response pathways, implying their potential associations with susceptibility to MAP. These genes included IL4, IL5, IL13, IRF1, MyD88, PACSIN1, DEF6, TDP2, ZAP70 and CSF2. By examining the QTLdb, the $32 \sim 33 \mathrm{Mb}$ region of BTA23 may be a genomic region associated with MAP infection.

\section{Additional files}

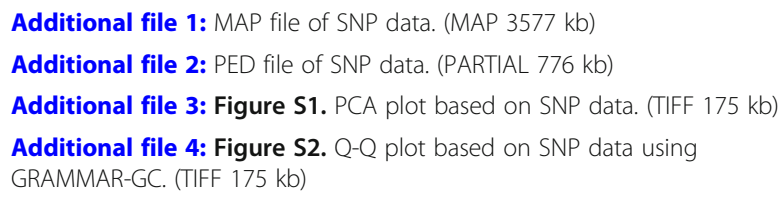

Additional file 5: Figure S3. Q-Q plot based on SNP data using ROADTRIPS. (TIFF $179 \mathrm{~kb}$ )

Additional file 6: Table S1. The features of genes based on GRAMMARGC. (XLSX $20 \mathrm{~kb})$

Additional file 7: Table S2. The features of genes based on RODATRIPS. (XLSX $15 \mathrm{~kb}$ )

Additional file 8: Table S3. The features of genes based on GRAMMARGC and RODATRIPS. (XLSX $26 \mathrm{~kb})$

Additional file 9: Table S4. Functional enrichment of GO and Pathway analysis of 343 genes. (XLSX $32 \mathrm{~kb}$ )

\section{Abbreviations}

GC: Genomic control; GRAMMAR-GC: Genome-wide Rapid Association using Mixed Model and Regression-Genomic Control; GWAS: Genome-wide association study; JD: Johne's disease; MAP: Mycobacterium avium subspecies Paratuberculosis; PCA: Principle component analysis; QQ: Quantile-quantile; QTL: Quantitative trait locus; SNP: Single nucleotide polymorphisms

\section{Acknowledgements}

Not applicable.

\section{Funding}

This work was supported financially by the National Natural Science Foundation (31472065, 31872330), Beijing Dairy Industry Innovation Team (BAIC06-2017/2018), Beijing Science and Technology Program (D171100002417001), earmarked fund for Modern Agro-industry Technology Research System (CARS-36), and the Program for Changjiang Scholar and Innovation Research Team in University (IRT_15R62IRT_15R62). Funding bodies did not have a role in the design of the study and collection, analysis, and interpretation of data, neither in writing the manuscript.

\section{Availability of data and materials}

All supporting data can be found within the additional files.

\section{Authors' contributions}

YG performed bioinformatics and statistical analysis, and also was a major contributor to manuscript preparation. JJ, SY, JC and BH performed experiments and sample collection. YW, YZ, YY, SZ and QZ participated in result interpretation, wrote, revised and approved the manuscript. LF and BC commented the manuscript and were major contribution to manuscript revision. DS conceived and designed the experiments and wrote the manuscript. All authors read and approved the final manuscript.

\section{Ethics approval and consent to participate}

All protocols for collection of the blood and hair samples of China Holstein cows were reviewed and approved by the Institutional Animal Care and Use Committee (IACUC) at China Agricultural University. Blood and hair samples were collected specifically for this study following standard procedures with the full agreement of the Beijing Dairy Cattle Center who owned the animals.
Consent for publication

Not applicable.

\section{Competing interests}

The authors declare that they have no competing interests.

\section{Publisher's Note}

Springer Nature remains neutral with regard to jurisdictional claims in published maps and institutional affiliations.

\section{Author details}

'Key Laboratory of Animal Genetics and Breeding of Ministry of Agriculture, National Engineering Laboratory of Animal Breeding, College of Animal Science and Technology, China Agricultural University, Beijing 100193, China. ${ }^{2}$ College of Veterinary Medicine, China Agricultural University, Beijing 100193, China. ${ }^{3}$ Department of Animal and Avian Sciences, University of Maryland, College Park, MD 20742, USA. ${ }^{4}$ Department of Animal and Veterinary Sciences, University of Vermont, Burlington, VT 05405, USA.

Received: 1 February 2018 Accepted: 18 December 2018 Published online: 27 December 2018

\section{References}

1. Clarke CJ. The pathology and pathogenesis of paratuberculosis in ruminants and other species. J Comp Pathol. 1997;116(3):217-61.

2. Whitlock RH, Buergelt C. Preclinical and clinical manifestations of paratuberculosis (including pathology). Vet Clin North Am Food Anim Pract. 1996:12(2):345-56

3. Koets AP, Adugna $G$, Janss $L L$, van Weering $H J$, Kalis $C H$, Wentink $G H$, et al. Genetic variation of susceptibility to Mycobacterium avium ssp. paratuberculosis infection in dairy cattle. J Dairy Sci. 2000;83:2702-8.

4. Mortensen H, Nielsen SS, Berg P. Genetic variation and heritability of the antibody response to Mycobacterium avium subspecies paratuberculosis in Danish Holstein cows. J Dairy Sci. 2004;87(7):2108-13.

5. Gonda MG, Chang YM, Shook GE, Collins MT, Kirkpatrick BW. Genetic variation of Mycobacterium avium ssp. paratuberculosis infection in US Holsteins. J Dairy Sci. 2006;89(5):1804-12.

6. Hinger $\mathrm{M}, \mathrm{Brandt} \mathrm{H}$, Erhardt $\mathrm{G}$. Heritability estimates for antibody response to Mycobacterium avium subspecies paratuberculosis in German Holstein cattle. J Dairy Sci. 2008:91(8):3237-44.

7. Attalla SA, Seykora AJ, Cole JB, Heins BJ. Genetic parameters of milk ELISA scores for Johne's disease. J Dairy Sci. 2010;93(4):1729-35.

8. Berry DP, Good M, Mullowney P, Cromie AR, More SJ. Genetic variation in serological response to Mycobacterium avium subspecies paratuberculosis and its association with performance in Irish Holstein-Friesian dairy cows. Livest Sci. 2010;131:102-7.

9. van Hulzen KJ, Nielen M, Koets AP, de Jong G, van Arendonk JA, Heuven HC. Effect of herd prevalence on heritability estimates of antibody response to Mycobacterium avium subspecies paratuberculosis. J Dairy Sci. 2011;94(2):992-7.

10. Küpper J, Brandt H, Donat K, Erhardt G. Heritability estimates for Mycobacterium avium subspecies paratuberculosis status of German Holstein cows tested by fecal culture. J Dairy Sci. 2012;95(5):2734-9.

11. Shook GE, Chaffer M, Wu XL, Ezra E. Genetic parameters for paratuberculosis infection and effect of infection on production traits in Israeli Holsteins. Anim Genet. 2012;43(Suppl 1):56-64.

12. Zare Y, Shook GE, Collins MT, Kirkpatrick BW. Short communication: heritability estimates for susceptibility to Mycobacterium avium subspecies paratuberculosis infection defined by ELISA and fecal culture test results in Jersey cattle. J Dairy Sci. 2014;97(7):4562-7.

13. Gao Y, Cao J, Zhang S, Zhang Q, Sun D. Short communication: heritability estimates for susceptibility to Mycobacterium avium ssp. paratuberculosis infection in Chinese Holstein cattle. J Dairy Sci. 2018;101(8):7274-9.

14. Pant SD, Verschoor CP, Schenkel FS, You Q, Kelton DF, Karrow NA. Bovine CLEC7A genetic variants and their association with seropositivity in Johne's disease ELISA. Gene. 2014;537(2):302-7.

15. Verschoor CP, Pant SD, You Q, Schenkel FS, Kelton DF, Karrow NA. Polymorphisms in the gene encoding bovine interleukin-10 receptor alpha are associated with Mycobacterium avium ssp. paratuberculosis infection status. BMC Genet. 2010;11:23. 
16. Pant SD, Verschoor CP, Skelding AM, Schenkel FS, You Q, Biggar GA, et al. Bovine IFNGR2, IL12RB1, IL12RB2, and IL23R polymorphisms and MAP infection status. Mamm Genome. 2011;22(9-10):583-8.

17. Pinedo PJ, Buergelt CD, Donovan GA, Melendez P, Morel L, Wu R, et al. Association between CARD15/NOD2 gene polymorphisms and paratuberculosis infection in cattle. Vet Microbiol. 2009;134(3-4):346-52.

18. Ruiz-Larrañaga O, Garrido JM, Iriondo M, Manzano C, Molina E, Koets AP, et al. Genetic association between bovine NOD2 polymorphisms and infection by Mycobacterium avium subsp. paratuberculosis in Holstein-Friesian cattle. Anim Genet. 2010;41(6):652-5.

19. Küpper JD, Brandt HR, Erhardt G. Genetic association between NOD2 polymorphism and infection status by Mycobacterium avium ssp. paratuberculosis in German Holstein cattle. Anim Genet. 2014;45(1):114-6.

20. Pant SD, Verschoor CP, Schenkel FS, You Q, Kelton DF, Karrow NA. Bovine PGLYRP1 polymorphisms and their association with resistance to Mycobacterium avium ssp. paratuberculosis. Anim Genet. 2011;42(4):354-60.

21. Pinedo PJ, Buergelt CD, Donovan GA, Melendez P, Morel L, Wu R, et al. Candidate gene polymorphisms (BolFNG, TLR4, SLC11A1) as risk factors for paratuberculosis infection in cattle. Prev Vet Med. 2009;91(2-4):189-96.

22. Ruiz-Larrañaga O, Garrido JM, Manzano C, Iriondo M, Molina E, Gil A, et al. Identification of single nucleotide polymorphisms in the bovine solute carrier family 11 member 1 (SLC11A1) gene and their association with infection by Mycobacterium avium subspecies paratuberculosis. J Dairy Sci. 2010;93(4):1713-21.

23. Ruiz-Larrañaga O, Garrido JM, Iriondo M, Manzano C, Molina E, Montes I, et al. SP110 as a novel susceptibility gene for Mycobacterium avium subspecies paratuberculosis infection in cattle. J Dairy Sci. 2010;93(12):5950-8.

24. Mucha R, Bhide MR, Chakurkar EB, Novak M, Mikula I Sr. Toll-like receptors TLR1, TLR2 and TLR4 gene mutations and natural resistance to Mycobacterium avium subsp. paratuberculosis infection in cattle. Vet Immunol Immunopathol. 2009;128(4):381-8.

25. Ruiz-Larrañaga O, Manzano C, Iriondo M, Garrido JM, Molina E, Vazquez P, et al. Genetic variation of toll-like receptor genes and infection by Mycobacterium avium ssp. paratuberculosis in Holstein-Friesian cattle. J Dairy Sci. 2011;94(7):3635-41.

26. Koets A, Santema W, Mertens H, Oostenrijk D, Keestra M, Overdijk M, et al. Susceptibility to paratuberculosis infection in cattle is associated with single nucleotide polymorphisms in toll-like receptor 2 which modulate immune responses against Mycobacterium avium subspecies paratuberculosis. Prev Vet Med. 2010;93(4):305-15

27. Pant SD, Schenkel FS, Verschoor CP, You Q, Kelton DF, Moore SS, et al. A principal component regression based genome wide analysis approach reveals the presence of a novel QTL on BTA7 for MAP resistance in Holstein cattle. Genomics. 2010;95(3):176-82.

28. Gonda MG, Kirkpatrick BW, Shook GE, Collins MT. Identification of a QTL on BTA20 affecting susceptibility to Mycobacterium avium ssp. paratuberculosis infection in US Holsteins. Anim Genet. 2007:38(4):389-96.

29. Settles M, Zanella R, McKay SD, Schnabel RD, Taylor JF, Whitlock R, et al. A whole genome association analysis identifies loci associated with Mycobacterium avium subsp. paratuberculosis infection status in US holstein cattle. Anim Genet. 2009;40(5):655-62

30. Kirkpatrick BW, Shi X, Shook GE, Collins MT. Whole-genome association analysis of susceptibility to paratuberculosis in Holstein cattle. Anim Genet. 2011;42(2):149-60.

31. Minozzi G, Buggiotti L, Stella A, Strozzi F, Luini M, Williams JL. Genetic loci involved in antibody response to Mycobacterium avium ssp. paratuberculosis in cattle. PLoS One. 2010;5(6):e11117.

32. Zanella R, Settles ML, McKay SD, Schnabel R, Taylor J, Whitlock RH, et al. Identification of loci associated with tolerance to Johne's disease in Holstein cattle. Anim Genet. 2011;42(1):28-38.

33. van Hulzen KJ, Schopen GC, van Arendonk JA, Nielen M, Koets AP, Schrooten C, et al. Genome-wide association study to identify chromosomal regions associated with antibody response to Mycobacterium avium subspecies paratuberculosis in milk of Dutch Holstein-Friesians. J Dairy Sci. 2012:95(5):2740-8.

34. Minozzi G, Williams JL, Stella A, Strozzi F, Luini M, Settles ML, et al. Metaanalysis of two genome-wide association studies of bovine paratuberculosis. PLoS One. 2012;7(3):e32578.

35. Zare Y, Shook GE, Collins MT, Kirkpatrick BW. Genome-wide association analysis and genomic prediction of Mycobacterium avium subspecies paratuberculosis infection in US Jersey cattle. PLoS One. 2014;9(2): e88380.
36. Alpay F, Zare Y, Kamalludin MH, Huang X, Shi X, Shook GE, et al. Genomewide association study of susceptibility to infection by Mycobacterium avium subspecies paratuberculosis in Holstein cattle. PLoS One. 2014;9(12): e111704.

37. Sallam AM, Zare Y, Alpay F, Shook GE, Collins MT, Alsheikh S, et al. An across-breed genome wide association analysis of susceptibility to paratuberculosis in dairy cattle. J Dairy Res. 2017;84(1):61-7.

38. Browning BL, Browning SR. A unified approach to genotype imputation and haplotype-phase inference for large data sets of trios and unrelated individuals. Am J Hum Genet. 2009;84(2):210-23.

39. Purcell S, Neale B, Todd-Brown K, Thomas L, Ferreira MA, Bender D, et al. PLINK: a tool set for whole-genome association and population-based linkage analyses. Am J Hum Genet. 2007:81(3):559-75.

40. Zimin AV, Delcher AL, Florea L, Kelley DR, Schatz MC, Puiu D, et al. A wholegenome assembly of the domestic cow, Bos taurus. Genome Biol. 2009;10(4):R42.

41. Haldar T, Ghosh S. Effect of population stratification on false positive rates of population-based association analyses of quantitative traits. Ann Hum Genet. 2012;76(3):237-45.

42. Yang J, Lee SH, Goddard ME, Visscher PM. GCTA: a tool for genome-wide complex trait analysis. Am J Hum Genet. 2011;88(1):76-82.

43. R Core Team. R: A language and environment for statistical computing. $R$ Foundation for statistical Computing Vienna, Austria. 2015. https://www.Rproject.org/. Accessed 21 Dec 2018.

44. Aulchenko YS, de Koning DJ, Haley C. Genomewide rapid association using mixed model and regression: a fast and simple method for genomewide pedigree-based quantitative trait loci association analysis. Genetics. 2007; 177(1):577-85.

45. Amin N, van Duijn CM, Aulchenko YS. A genomic background based method for association analysis in related individuals. PLoS One. 2007;2(12):e1274.

46. Aulchenko YS, Ripke S, Isaacs A, van Duijn CM. GenABEL: an R library for genome-wide association analysis. Bioinformatics. 2007;23(10):1294-6.

47. Thornton T, McPeek MS. ROADTRIPS: case-control association testing with partially or completely unknown population and pedigree structure. Am J Hum Genet. 2010;86(2):172-84.

48. Wellcome Trust Case Control Consortium. Genome-wide association study of 14,000 cases of seven common diseases and 3,000 shared controls. Nature. 2007:447(7145):661-78.

49. Xie C, Mao X, Huang J, Ding Y, Wu J, Dong S, et al. KOBAS 2.0: a web server for annotation and identification of enriched pathways and diseases. Nucleic Acids Res. 2011:39(Web Server issue):W316-22.

50. Hu ZL, Fritz ER, Reecy JM. AnimalQTLdb: a livestock QTL database tool set for positional QTL information mining and beyond. Nucleic Acids Res. 2007; 35(Database issue):D604-9.

51. Chen L. Co-inhibitory molecules of the B7-CD28 family in the control of Tcell immunity. Nat Rev Immunol. 2004;4(5):336-47.

52. Küpper J, Brandt H, Donat K, Erhardt G. Phenotype definition is a main point in genome-wide association studies for bovine Mycobacterium avium ssp. paratuberculosis infection status. Animal. 2014;8(10):1586-93.

53. Coussens PM. Mycobacterium paratuberculosis and the bovine immune system. Anim Health Res Rev. 2001;2(2):141-61.

54. Coussens PM, Pudrith CB, Skovgaard K, Ren X, Suchyta SP, Stabel JR, et al. Johne's disease in cattle is associated with enhanced expression of genes encoding IL-5, GATA-3, tissue inhibitors of matrix metalloproteinases 1 and 2 , and factors promoting apoptosis in peripheral blood mononuclear cells. Vet Immunol Immunopathol. 2005:105(3-4):221-34.

55. Sohal JS, Singh SV, Tyagi P, Subhodh S, Singh PK, Singh AV, et al. Immunology of mycobacterial infections: with special reference to Mycobacterium avium subspecies paratuberculosis. Immunobiology. 2008; 213(7):585-98.

56. Stabel JR. Transitions in immune responses to Mycobacterium paratuberculosis. Vet Microbiol. 2000;77(3-4):465-73.

57. Koets A, Rutten V, Hoek A, van Mil F, Müller K, Bakker D, et al. Progressive bovine paratuberculosis is associated with local loss of CD4(+) T cells, increased frequency of gamma delta T cells, and related changes in T-cell function. Infect Immun. 2002;70(7):3856-64.

58. Lohoff M, Ferrick D, Mittrucker HW, Duncan GS, Bischof S, Rollinghoff M, et al. Interferon regulatory factor-1 is required for a T helper 1 immune response in vivo. Immunity. 1997;6(6):681-9.

59. McElligott DL, Phillips JA, Stillman CA, Koch RJ, Mosier DE, Hobbs MV. CD4+ T cells from IRF-1-deficient mice exhibit altered patterns of cytokine expression and cell subset homeostasis. J Immunol. 1997;159(9):4180-6. 
60. Taki S, Sato T, Ogasawara K, Fukuda T, Sato M, Hida S, et al. Multistage regulation of Th1-type immune responses by the transcription factor IRF-1. Immunity. 1997;6(6):673-9.

61. He J, You X, Zeng Y, Yu M, Zuo L, Wu Y. Mycoplasma genitalium-derived lipid-associated membrane proteins activate NF-kappaB through toll-like receptors 1, 2, and 6 and CD14 in a MyD88-dependent pathway. Clin Vaccine Immunol. 2009;16(12):1750-7.

62. Pérez-Otaño I, Luján R, Tavalin SJ, Plomann M, Modregger J, Liu XB, et al. Endocytosis and synaptic removal of NR3A-containing NMDA receptors by PACSIN1/syndapin1. Nat Neurosci. 2006;9(5):611-21.

63. Esashi E, Bao M, Wang YH, Cao W, Liu YJ. PACSIN1 regulates the TLR7/9mediated type I interferon response in plasmacytoid dendritic cells. Eur J Immunol. 2012;42(3):573-9.

64. Gupta S, Lee A, Hu C, Fanzo J, Goldberg I, Cattoretti G, et al. Molecular cloning of IBP, a SWAP-70 homologous GEF, which is highly expressed in the immune system. Hum Immunol. 2003;64(4):389-401.

65. Rodrigues-Lima F, Josephs M, Katan M, Cassinat B. Sequence analysis identifies TTRAP, a protein that associates with CD40 and TNF receptorassociated factors, as a member of a superfamily of divalent cationdependent phosphodiesterases. Biochem Biophys Res Commun. 2001 285(5):1274-9.

66. Gu Y, Chae HD, Siefring JE, Jasti AC, Hildeman DA, Williams DA. RhoH GTPase recruits and activates Zap70 required for T cell receptor signaling and thymocyte development. Nat Immunol. 2006;7(11):1182-90.

67. Shirkani A, Shahrooei M, Azizi G, Rokni-Zadeh H, Abolhassani H, Farrokhi S, et al. Novel mutation of ZAP-70-related combined immunodeficiency: first case from the National Iranian Registry and review of the literature. Immunol Investig. 2017:46(1):70-9.

68. Leite FL, Eslabão LB, Pesch B, Bannantine JP, Reinhardt TA, Stabel JR. ZAP-70, CTLA-4 and proximal T cell receptor signaling in cows infected with Mycobacterium avium subsp. paratuberculosis. Vet Immunol Immunopathol. 2015;167(1-2):15-21.

69. Murphy JM, Soboleva TA, Mirza S, Ford SC, Olsen JE, Chen J, et al. Clarification of the role of N-glycans on the common beta-subunit of the human IL-3, IL-5 and GM-CSF receptors and the murine IL-3 beta-receptor in ligand-binding and receptor activation. Cytokine. 2008;42(2):234-42.

Ready to submit your research? Choose BMC and benefit from:

- fast, convenient online submission

- thorough peer review by experienced researchers in your field

- rapid publication on acceptance

- support for research data, including large and complex data types

- gold Open Access which fosters wider collaboration and increased citations

- maximum visibility for your research: over $100 \mathrm{M}$ website views per year

At $\mathrm{BMC}$, research is always in progress.

Learn more biomedcentral.com/submissions 